Andrews University

Digital Commons @ Andrews University

Faculty Publications

$9-14-2020$

\title{
What We've Managed to Transcribe Thus Far: Lessons from the Blythe Owen Letter Transcription Project
}

Marianne Kordas

Andrews University, kordas@andrews.edu

Follow this and additional works at: https://digitalcommons.andrews.edu/pubs

Part of the Musicology Commons

\section{Recommended Citation}

Kordas, Marianne, "What We've Managed to Transcribe Thus Far: Lessons from the Blythe Owen Letter Transcription Project" (2020). Faculty Publications. 1434.

https://digitalcommons.andrews.edu/pubs/1434

This Article is brought to you for free and open access by Digital Commons @ Andrews University. It has been accepted for inclusion in Faculty Publications by an authorized administrator of Digital Commons @ Andrews University. For more information, please contact repository@andrews.edu. 


\section{What We've Managed to Transcribe Thus Far: Lessons from the Blythe Owen Letter Transcription Project}

\section{Marianne Kordas}

To cite this article: Marianne Kordas (2020) What We've Managed to Transcribe Thus Far: Lessons from the Blythe Owen Letter Transcription Project, Music Reference Services Quarterly, 23:3-4, 153-170, DOI: 10.1080/10588167.2020.1816039

To link to this article: https://doi.org/10.1080/10588167.2020.1816039

曲 Published online: 14 Sep 2020.

Submit your article to this journal $\widetilde{x}$

山ll Article views: 117

Q View related articles ¿

View Crossmark data 


\title{
What We've Managed to Transcribe Thus Far: Lessons from the Blythe Owen Letter Transcription Project
}

\author{
Marianne Kordas \\ Andrews University, Berrien Springs, Michigan, USA
}

\begin{abstract}
In 2016, the music librarian at Andrews University in Berrien Springs, MI launched a project to transcribe approximately 2,000 letters by twentieth-century American composer Blythe Owen into typed, keyword-searchable documents. The goal of the transcription project is to make these letters more accessible beyond their current archival setting, and thereby lay the foundation for further inquiry into Owen, her works, and the people she knew - among them pianist and pedagogue Rudolf Ganz, African-American composer Florence Price, and composition teacher Nadia Boulanger. Managing such a large project has proven challenging, but worth the effort. This article describes the methodology, successes, challenges, and current progress of the Owen letter transcription project, including the employment of two graduate assistants in the transcription process over the past four years. The benefits of involving student assistants in the research process in an archive outweigh the challenges of mentoring and supervising the creation of the transcription documents.
\end{abstract}

\section{ARTICLE HISTORY}

Received 13 May 2020

Accepted 24 August 2020

\section{KEYWORDS}

Project management;

archival collections;

twentieth-century American music; women composers

\section{Introduction}

Andrews University in Berrien Springs, MI has the privilege of holding the papers of American composer Blythe Owen (1898-2000). Owen was one of the first women to earn a PhD in composition from the Eastman School of Music, studying with Howard Hanson and Bernard Rogers, and graduating in $1953 .{ }^{1}$ While the core of Dr. Owen's career was spent in Chicago, ${ }^{2}$ she held an appointment from 1965 to 1974 as a professor of piano, theory, and composition at Andrews University, and was also composer-in-residence. ${ }^{3}$ She continued to teach part-time for the university into the mid-1980s and gave private piano lessons at home for five to ten years after that. Dr. Owen made an initial deposit of papers to the Andrews University archive in 1991; a second deposit was made via her personal representative in $1997 .{ }^{4}$ Subsequent donations of materials continue to be made by family, friends, and colleagues.

CONTACT Marianne Kordas kordas@andrews.edu Andrews University, Hamel Hall 110, 8495 University Blvd, Andrews University, Berrien Springs, MI 49104

(c) 2020 The Author(s). Published with license by Taylor \& Francis Group, LLC. 
Owen's archival collection contains a variety of materials, including music manuscripts, scores, photographs, diaries, sound recordings, and various types of personal documents. One of the largest sections of the fonds - a term archivists use to describe an individual or entity's entire collection - consists of Owen's letters to her mother, Minnie Perkins Owen, from 1919 until the early 1960s. About half of this correspondence was discovered at Owen's estate sale in the summer of 1997 by the Andrews University campus historian and purchased for the university archives. ${ }^{5}$ Dr. Meredith Jones Gray recalls:

I went to the auction at Blythe Owen's house just because I like estate auctions - I don't remember what year that was, but Jim Ford probably has the information about when they acquired the collection. When I got there I discovered these piles and piles of letters; I think they were being sold mostly for the old stamps on the envelopes. I started reading a few of them and realized that this was a detailed account of her life abroad. What I initially looked at were letters from Owen from Paris. Even I recognized the names of famous musicians! I really panicked that they would sell before I could rescue them. That was pre-cellphone, for me at least. I think I found a phone in the house and started calling around. I was so nervous. I can't remember who I called first but very soon Jim Ford was brought into the conversation and came right over to the auction with the authority to buy the materials. I was so happy to see him! I can't remember whether I did the bidding or Jim did - I think it was him. We didn't have a huge amount of competition, as I remember it, and we got the whole collection. I'm sure he can tell you what it cost. I can remember boxing it all up - Jim there in his jacket and tie is the image I have. So I was the one who discovered that the material was there (and I was astounded that it hadn't been saved) and fortunately had the good sense to realize that it was something worth rescuing. But Jim was the hero who also went into high gear, dropped everything, and came over to actually seal the deal. My guess is that we came within about half an hour to an hour of never having the whole collection. ${ }^{6}$

A donation of family documents by Owen's second cousin Donna Kennedy in 2008 helped to expand this letter series and provide further information on Owen's life during the 1950s and 1960s. ${ }^{7}$ Thanks to these two acquisitions there are now approximately 2,000 letters from Owen to her mother available for research. In addition to documenting Owen's own life and work, these letters discuss a spectacular number of acquaintances who are important to the history of both American and French music-making in the twentieth century: Agnes Pillsbury, Rudolf Ganz, Robert and Gabby Casadesus, Florence Price, Percy Grainger, Howard Hanson, and Nadia Boulanger.

\section{Impetus for the transcription project}

My relationship with the Owen correspondence is a long one. During my undergraduate years, I worked as a student assistant at the Music Materials Center of the James White Library, the music library where I am currently the director. Linda Mack, the music librarian at the time and my supervisor, was conducting research on Blythe Owen's life with the intention of writing 
a biography of the composer. Those efforts included finding original materials for inclusion in the archives, performing oral history interviews with Owen's friends and colleagues, and gathering information from the composer's correspondence to create a website with basic information about Owen's life and works. ${ }^{8}$

In July 2007, during the summer between my undergraduate and graduate studies, Mack asked me to use my background in calligraphy to transcribe a letter from July 1, 1949, that describes Owen's trans-Atlantic flight to France to study with Nadia Boulanger at Le Conservatoire Américain in Fontainebleau. ${ }^{9}$ The letter is difficult to read in the original because it is written in portrait direction on one side, and in landscape direction on the other side. Bleed-through and ink-creep produce a crosshatched effect. A careful, typed transcription, therefore, makes scholarship about the Fontainebleau trip much easier. The experience of transcribing this letter taught me what a difference a clearly typed transcription could make for the end user, and it sparked my interest in conducting research from primary sources. During the subsequent summer of 2008 I helped to unpack, index, and process the donation of materials from Donna Kennedy. ${ }^{10}$ Throughout the six years I spent at the University of Wisconsin-Milwaukee pursuing dual graduate degrees in musicology and library science I stayed in touch with Mack about the progress of the Owen biography project and provided various levels of research help.

When Mack retired in 2012 and I succeeded her as director of the Music Materials Center, I wanted to share with others the excitement of research and discovery I had experienced as an undergraduate when assigned to work with primary, archival sources. Thanks to the efforts of Mack and others, the amount of material collected by and about Owen had grown since the first donation in 1991, but it was still largely unprocessed and loose in cardboard boxes in the backlog of the Center for Adventist Research (CAR). Within my first two years as music librarian, I made it a priority to coordinate with Jim Ford, associate director of the Center for Adventist Research, to employ student assistants with backgrounds in music to finish reorganizing and processing the Owen collection as a whole. Our team finished updating the finding aid and properly storing the scores, notebooks, recordings, and manuscripts in 2015.

As Mack continued in her retirement to work toward a biography of Owen, she would occasionally ask me from her new home in Denver, CO, for PDF scans of various letters with which to do research and fact-checking. After several years of providing sporadic research support via letter scanning with the help of various undergraduate and graduate student library assistants, I decided in the summer of 2016 that a more systematic approach was needed to facilitate access to these fascinating letters. ${ }^{11}$ With the help of my graduate assistant at the time, I launched a formal project to transcribe the entire series 
of handwritten letters from Blythe Owen to her mother into typed, keywordsearchable documents. Although there are other letters in the collection as a whole that are of historical interest, such as letters from Owen's family members, friends, and musical associates, ${ }^{12}$ I thought it crucial to start with a focus on the letters from Owen herself. I believe this is the best way to allow her to speak for herself to posterity and form the basis of an accurate biographical narrative. ${ }^{13}$

The end goals of the Blythe Owen letter transcription project are multifaceted. The first goal is to create a keyword-searchable database of letter transcriptions from which research questions can be answered, allowing for analysis of the letter contents in powerful new ways. Secondly, if possible, I would like to publish the letters in a permanent, print monograph. My hope is that the letter transcriptions can, ultimately, form the bedrock of any future scholarship on Owen, her compositions, her creative milieu in twentiethcentury Chicago, and her professional relationships with leading musicians of her day.

Managing a project of this size has proven to be difficult, but worth the effort. This article describes the methodology, successes, challenges, and current status of the Owen letter transcription project, including the employment of two graduate assistants in the transcription process over the past four years. ${ }^{14}$ I argue that the benefits of exposing student assistants to primary sources and the research process in an archive outweigh the challenges of mentoring and supervising the creation of the transcription documents and managing a large-scale, long-term project.

\section{Methodology}

The inspiration for a project of such a large scope was taken from publications such as the collected letters of the Mozart family and the transcription of Alma Mahler's early diaries. ${ }^{15}$ No single theory or methodology has served as the basis for the Blythe Owen letter transcription project, although its aims and intellectual framework have been deeply influenced by the feminist and sociocultural interpretive trends of post-1980s "new" musicology which insist that American and female composers are as worthy of study as European and male composers. ${ }^{16}$ An enthusiasm for sharing the life of Dr. Owen with a wider public and a desire for systematic representation of the correspondence have been my primary, driving motivations since the beginning of the project, and continue to be so.

With approximately 2,000 letters to transcribe, it was clear that the scope of the transcription project was too large to attempt by myself. Thus, I decided to delegate the work of creating the initial drafts of the transcriptions to my graduate assistant. At first, this began as a way to guarantee enough work hours for an assistant with limited duties during the 2016 summer term when 
my branch music library did not have as many operating hours as during the school year. When the first graduate assistant left upon completion of her program and I hired a replacement in June 2018, I made the letter transcription project the primary focus of the second student's job assignment.

From the start, I have insisted on using best practices for source transcription and editing. This includes placing question marks after conjectured spellings of words, using brackets for editorial interpolations, and so forth. ${ }^{17}$ I also made the editorial decision to silently correct Owen's occasional habit of not dotting her i's or crossing her t's. In so doing I aim to have my team transmit the meaning of a word rather than a slavish transliteration of it. ${ }^{18}$

At first, transcriptions were emailed to me as Word documents. This proved cumbersome, so the first graduate assistant and I switched to using Google Drive and Google Docs. Using these G Suite products has allowed for transcriptions to be more securely and conveniently shared. I appreciate the elastic and accommodating features of a cloud-based data and document system: the automatic saving of documents; the flexible, synchronous or asynchronous sharing of transcriptions or correction to transcriptions; the ability for all editors to comment and then have comments marked as resolved; the option of marking text in different colors to signal the need for editing or problem checking; and the possibility of crowd-based creation and editing.

We currently use two main methods for producing a transcription: from an original, holograph letter housed in the archive, or from a PDF scan stored in our project's Google Drive. ${ }^{19}$ In either case, the graduate assistant types out the transcriptions into a Word document, saves it locally on the personal laptop in use, and then copy-pastes the transcription into a Google Doc in the project's cloud drive. All transcriptions are stored in shared Google Drive folders organized with a nesting taxonomy of Owen Project $>$ Transcribed Letters $>$ Year $>$ Month $>$ Date on Letter, with the date of the letter written in descending order from largest to smallest unit (1947.05.23) in order to allow for correct machine-based sorting in chronological order within the Month folder.

A quality control spreadsheet made with Google Sheets is used both to index the contents of the letter collection at a more granular level than is detailed in the collection register, and to keep track of progress and challenges in the transcription process. The first round of quality control, such as checking for spelling and typos, may be done by the transcriptionist after a few days or weeks have lapsed (enough time to give a fresh perspective), or by another person at another time. These actions, and who did them, are all recorded in the spreadsheet.

Each week, the student research assistant is asked to submit an e-mail to me briefly detailing the work accomplished that week along with any challenges. This weekly "work diary" allows for clear goal setting and a sense of accomplishment for both the student and the project supervisor. I meet with students 
on a weekly or bi-weekly basis for mentoring, problem-solving, and discussion of discoveries and questions related to Owen, her world, or the contents of her letters. Occasionally a student assistant will ask me for an appointment in the archives to jointly review a difficult or puzzling section of handwriting in a specific letter.

\section{Successes}

To date, perhaps the greatest success of the letter transcription project has been in teaching me how to manage large, long-term projects, both through the things that have gone well and the things that could be improved.

In just over four years, from the summer of 2016 until the present, my two graduate student assistants have been able to transcribe approximately 820 letters - almost half of all the correspondence that is the focus of our project. Most of the letters from 1919-1935 and 1943-1955 are now in rough draft form. Furthermore, about 400 of these rough draft transcriptions have undergone the first of what are planned to be three rounds of quality control checking. ${ }^{20}$

The ease and flexibility of using a cloud-based system such as Google Drive for creating, storing, reviewing, and correcting the letter transcriptions has been indispensable to the success of the project. As mentioned above, using Google Docs enables asynchronous editing and commenting on the transcriptions for a given week. Since my student assistants mainly work from the university archives, which are located in a separate building than my office in the music library, or from home (sometimes in another country), using a cloud-based system allows me to supervise my research assistant's work without having to be physically present during the typing of the transcriptions.

One of the things I am most proud of with the transcription project is that creating this database of hundreds of documents has allowed me to harness the power of keyword searching for my other large-scale project centered on Owen: a critical edition of her 1946 violin sonata. After two years of my graduate assistants creating letter transcriptions, in October 2018, I was able to conduct a database search for the keywords "violin and sonata" that generated a list of letters where the sonata is mentioned. The letters in this list pinpointed crucial information about the genesis and performance history of the violin sonata in a matter of minutes, something that would have taken a good deal of slogging and a keen eye when reading the manuscripts unaided. The database's search engine can never replace the serendipitous, enthralling experience of reading through the entirety of an archival collection, but it does add a powerful new tool to existing research strategies.

Another success has been in how my two graduate research assistants have become engaged and interested in the history and stories found in the letters as they transcribed them. I have watched both of them grow from merely typing 
the transcriptions because it is their job to becoming really engaged with the sources and excited about Dr. Owen, her life, her compositions, and the people in the world she inhabited. Scholarly literature about music history pedagogy has recently discussed how students are more engaged when exposed to the process of writing history through the use of primary sources - how one builds historical narrative out of an interrelationship between documents, clues, questioning, and accumulated expertise. ${ }^{21}$ My experience both as a student library assistant and as a project manager mentoring my own student workers validates the worth of engaging with primary sources as a way to make music history interesting and relevant. Rather than being a dull string of names and dates to memorize out of a textbook, transcribing primary sources can spark curiosity into further research about persons, compositions, and other cultural aspects thus encountered, making an era come alive in a potent way.

\section{Challenges of various sorts}

Any endeavor the size of the letter transcription project is bound to encounter challenges. Indeed, the project would probably have proceeded more smoothly if I had not originally conceived of it precisely as a fairly straightforward project: transcribe all the letters with the help of graduate assistants, proofread and edit the typed drafts, create a few critical apparatuses such as indexes of names and places, find a willing publisher, and release a thick volume in a short run of monographs to a suitably small and niche audience.

I now know that creating an edition of any original document is a highly subjective, work-intense process that requires many layers of expertise and interpretation, not just a one-to-one objective transmutation from one type of source to another. ${ }^{22}$

Some of the challenges encountered in the Owen letter transcription project derive from human miscalculation. Other challenges have come from the limits of technology, the nature of primary the sources being handled, and the condition of the collection. In this section, I will describe the various challenges my team has worked through over the past four years.

\section{Human miscalculations}

The first area of challenge, and perhaps the one most difficult to manage, are issues arising from human miscalculation and lack of knowledge or planning. In retrospect, there are several procedures I regret not instituting from the beginning of the project.

Instead of diving straight into scanning and transcribing, I wish I had asked my first graduate assistant to start by creating a more detailed inventory spreadsheet of the letters than what the archival register provides. This would have given us a system from the very beginning to track the progress 
of the project, the accuracy of the work, and any issues in the letters that needed direct attention or intervention from me. After the first graduate assistant left, I asked the second, newly hired graduate assistant to doublecheck the existing transcriptions and create a quality-control spreadsheet in our shared Google Drive to document which letters from the archive have and have not - been transcribed yet. This spreadsheet also tracks if a letter or postcard has been scanned, who the letter is from, to whom it is addressed, the date of composition, and any descriptive notes or flags for help. ${ }^{23}$ This has proven a good system for documenting completed transcriptions, which transcriptions may have been skipped and still need to be drafted, errors or questions in transcriptions, or holographs that the student transcriptionist feels are too illegible to transcribe without my help. Overall, I now have a much better grasp of exactly what is in the letter collection, by whom, and where any particular letter from any specific year is located. ${ }^{24}$

As the project progressed, I also perceived a need for keeping track of tasks, problems, and accomplishments encountered in the transcription process during a work week.

Since my research assistants were largely working remotely, as mentioned earlier, it became imperative to have a method of communication and accountability that did not rely on my physical presence. Therefore, I implemented a system of requiring weekly "work diary" e-mails containing updates and questions. This method has been effective in keeping communication open and the transcription project moving forward. These work diaries enable student assistants to track their accomplishments, document problems and progress, and verify what they have accomplished while clocked in for work. Psychologically, it's reassuring to see one's progress in the midst of a monumental project involving multiple people over long stretches of time. As a supervisor, this work diary system has proven invaluable for exercising greater control over the project and removing ambiguity about tasks, progress, and problems needing resolution.

Each employee comes to their tasks with certain personality traits, strengths, weaknesses, and experience. At my university, we pride ourselves on the wide diversity of international backgrounds among our students, faculty, and staff. Hiring graduate students whose second (or third or fifth) language is English, however, can pose challenges when working with primary sources often written in casual English over the course of the twentieth century. If one hasn't read classic Nancy Drew or watched films starring Cary Grant, one may find early-twentieth-century American idioms, acronyms, and phrasal verbs - such as WASP, "just something," "sassy," "swell," "run around," "lay of the land" - incomprehensible. ${ }^{25}$

When hiring additional students to join my transcription team, whether or not they are native speakers of English, I plan on giving them a sample passage from the letters to transcribe as a way to test their accuracy and 
comprehension. It may also be helpful to have them read a mid-twentiethcentury American novel, watch a classic Hollywood film, and listen to old-time radio broadcasts to get the sound of the 1920s, 1930s, and 1940s in their ears. It may sound like a strange way to train student researchers, but it will fill an experiential knowledge gap when making judgment calls associated with vintage archival transcription.

It can also be a challenge to ask graduate music students who may not have wide exposure to twentieth-century American and French composers, or who do not know much about Chicago, to recognize when they are transcribing an important name or event. Furthermore, students who have not been required to learn cursive handwriting in elementary school may find working in an archive with older sources difficult. My second graduate assistant expressed surprise that Owen's letters are in longhand, rather than the block-style print handwriting more commonly taught now, if at all.

These gaps in scholarly knowledge or practical aptitude must be addressed during training and the weekly or bi-weekly mentoring meetings over the course of a project. Not only are the students performing a work task, they must be encouraged to see that they broadening their range of scholarly and professional skills.

\section{Limits of technology}

While various technologies have been core to the success of this project (such as electricity, computing, laptops, word processing software, the Internet, Wi$\mathrm{Fi}$, and cloud-based data storage), technology does have its limits. During the course of this project, we encountered challenges with speech-to-text software, the limitations and features of Google Drive, the advantages and disadvantages of transcribing from PDF, and the logistics of quality control and data loads when performing PDF scanning.

My first graduate assistant used free speech-to-text software to create early transcriptions. The student thought this would be an efficient way to create more transcriptions each day. Unfortunately, these speech-to-text transcriptions proved to be largely unintelligible and needed to be retyped while performing quality control checks on the existing transcriptions during the summer of 2019. I believe that the Owen letters contain too many specialized musical terms and mid-twentieth-century American idiomatic expressions for speech-to-text transcription to be effective. This experience, however, was a good lesson in how sometimes a process that appears to be more timeconsuming (typing) may actually be more efficient and precise than using a more "techy" method. Speech-to-text can be an excellent means of drafting papers and e-mails, especially for those with physical challenges, learning divergences, or anxiety disorders. But in the context of this transcription 
project, speech-to-text was not a good fit - the tool must match the task at hand.

While using Google Drive has overall been a good thing, there are limits to the amount of data storage for personal accounts, for example, and I started the project before our university adopted Google products for its institutional e-mail and cloud-drive suite. Thus, the folders are embedded in my personal Gmail address and not in my institutional Google Drive. One of my initial oversights was not being the creator of the root folders in Google Drive for the transcription project. As a result, I had to request editing and ownership privileges from the graduate assistant after the project had begun. I also worry that it might be too easy for entire folders of transcriptions to be accidentally deleted by a person who has editing privileges. I am currently researching how to handle these storage, security, and access issues.

Perhaps the most predominant challenges stemming from technology in our project are the advantages and disadvantages of transcribing from PDF scans. The advantages are significant, especially in our current pandemic environment where many people are needing to work from home. When reading from scans instead of original manuscripts, transcription work becomes portable, flexible, and modular. One is not bound to working only when the archive is open to the public; a transcriber can telecommute, even internationally, as long as one has a large stock of scans to work from. Furthermore, the initial round of quality checking can be performed by comparing the transcription against the contents of a scan.

Yet, there are also disadvantages of working from a scan instead of directly from original materials. The starkest disadvantage is that one is separated from the physical, forensic clues an original document can offer. The transcriber loses details of penmanship, the ebb and flow of ink - it can be hard to tell if an errant dot is a fly speck or dust particle on the scan, or an actual jot or tittle by the author. Fingermarks and greasy corners that speak of wear and use are not as obvious. I have even occasionally seen drip marks on letters that make one wonder if the reader cried over it, laid it open on a windowsill that got some rain, or accidentally spilled a glass of water. These types of clues are not as evident in a typical scan. Furthermore, thin types of paper or pages that have a significant amount of ink bleeding can render handwriting indecipherable because it is impossible to distinguish what words belong to one side of the page, and which to the other. Lastly, inconsistencies in quality control when creating scans have plagued our project: low $\mathrm{DPI}^{26}$ that renders text as lessthan-crisp, and missing or out-of-sequence pages.

Since the impetus for the project came from research reference requests for digital scans of various letters from Owen's correspondence, my initial thought was to digitize all the letters and post them on a digital archive platform as well as transcribe them. But over time it has become clear that digitization of the entire corpus of letters will need to be its own project. It is one thing to scan 
various letters into PDF and upload them into Google Drive folders for the practical purposes of reference checking or transcription when telecommuting. It is quite another to have consistent quality control measures in place that assure high-resolution DPI, correct orientation and number of pages, consistent margins and size scale, proper color facsimiles, and the inclusion of both sides of an envelope in a single file in order to post that file on a digital platform accessible to either internal or external users.

So many different student assistants have performed scanning over the past five years with such wide ranging standards of quality that I believe it would be best to start over from the beginning. The large size of files and amount of data that would be generated by this future project will require good planning, proper processing protocols, and a robust data platform for storage and access. If I decide that these files should be made available to the public, I will need to work with personnel in the Center for Adventist Research and the Adventist Digital Library (ADL) to find a digital archive platform that can handle that amount of data; since ADL already uses a Fedora-based platform for their collections, Fedora may be an option.

\section{Challenges rooted in the collection and the materials}

As mentioned earlier, the collection of letters forming the focus of this transcription project is the result of a serendipitous discovery by Dr. Jones Gray and the collecting efforts of Linda Mack in correspondence with Owen's remaining family members, not a planned donation to the archives. The nature of these acquisitions and their subsequent processing history pose some challenges to researchers in general and to my transcribing team in specific.

The primary challenge is that some years and months of letters are absent from the archive. It is not yet clear, for example, why letters from 1930 and 1931 are not extant in the collection, or why certain months in certain years are skipped when the rest of the year is complete. My working hypothesis is that Owen's mother saved most of the correspondence she received from her daughter from 1919 until Owen moved back to the Pacific Northwest in 1961 to teach at Walla Walla College (now Walla Walla University). ${ }^{27}$ This would explain the scope of the collection. During those four decades, however, there were periods of time when Owen stayed with her mother, or vice versa, sometimes for weeks or months at a time. This, along with the rise of personally owned home telephones during the twentieth century, could explain some of the gaps in correspondence. It makes sense that Owen would have taken many of her mother's belongings, including the saved correspondence, with her to her new job at Andrews University in the summer of 1965 after her mother's death in the spring of $1964 .^{28}$ 
A second challenge rooted in the physical archival collection is that some letters appear to have had pages mixed up during their processing into folders at the archive or during the research or scanning process by various students and scholars over the years. This is especially evident in the correspondence from 1945.

An additional challenge with the materials of the collection is that either prior to or during processing for the archives, multiple letters became separated from their envelopes, resulting in the creation of an "orphan envelopes" folder ${ }^{29}$ Archivist Jim Ford has stated

This is largely due to the fact that most of the letters were not in envelopes when received. Therefore, the envelopes were loose. These envelopes lack date information or whatever might be there is indecipherable. It is our practice now to keep envelopes with the letters as much as possible. It is possible a previous processor may have done some separation before it was caught. I do not remember this. ${ }^{30}$

Regardless of why the envelopes became separated from their corresponding letters, it is an unfortunate situation since envelopes provide crucial metadata for letters, such as postmarks and addresses, and additional useful information, such as postscripts and notations from recipients.

Lastly, the physical condition of some letters poses a challenge to legibility and transcription. A letter from May 3, 1926, for example, was written in pencil and has faded into illegibility. Another example is the letter from May 15, 1934, which has two cuts across the pages, and the pieces cut off are not extant. There are also holes in several letters, either from pages being folded over and over from re-reading, or from ink eating through the paper. Many letters suffer from ink-creep and bleed-through. One particularly difficult letter to transcribe was the one mentioned earlier from July 1, 1949, that describes Owen's flight from Chicago to the airfield in Orly, France on her way to study at the Le Conservatoire Américain in Fontainebleau.

\section{Current status and future goals}

My current graduate research assistant had originally stated that it was his personal goal to be done by the end of summer 2020 with the quality control checks for the 1947-1955 transcriptions created by the first graduate assistant. However, since our university archive is now closed to the public until Fall 2020 due to COVID-19, we may need to be creative and instead continue filling in first-draft transcriptions from scans of letters that still need to be read and indexed. ${ }^{31}$

Once it is again possible to access the archives, I would like to turn to completing an inventory of the remaining letters from the latter half of the 1950s forward, creating transcriptions as necessary, thereby taking the 
transcriptions to the end of the collection. Then, in the future this assistant (or whomever I hire next) can continue to work on transcribing the letters from 1935 to 1943 that still need to be drafted as well as performing quality control checks for existing drafts for the collection as a whole.

If we have jumped around in the sequence of years transcribed, rather than using a purely chronological approach to transcribing the letters straight through from 1919 to 1964, it is due to practical and logistical employment considerations over the past four years. Moreover, because of my desire to use the letters to inform my research on Owen's violin sonata written in 1946, I chose to prioritize transcribing the letters from 1943 to 1955. My first graduate assistant, therefore, wrote the first drafts of the transcriptions for this time period during the summers of 2016 and 2017; of these, the second graduate assistant has performed the inventory and quality control checks up through 1949.

During the summer of 2019, however, the second graduate assistant needed to telecommute from home in another country. Since he couldn't work directly from the holographs in the archive to perform quality checks on the existing transcriptions, I allowed him to skip back to the start of the collection and make scans of the earliest letters from 1919 forward. He then transcribed those from home, and then double-checked problem areas from the original manuscripts once he returned for the fall 2019 semester. This spring he continued transcribing up to 1935 , but then returned to performing quality control and supplying missing transcriptions for the work done by the first graduate assistant from the 1949 letters forward.

This hop-scotch progression through the collection of letters has not been as straightforward as planned, nor ideal, but I have tried to remain flexible in light of various circumstances in order to continue moving forward. As the implications of the current COVID-19 pandemic unfold throughout the summer and fall of 2020, maintaining a flexible and creative attitude will be even more vital to keep us on track.

Since my current graduate research assistant is planning to graduate in August 2020, over the next two to three years I anticipate needing to hire a third research assistant to perform quality control on the inventory list and all transcriptions created by the first and second research assistants.

We will need, furthermore, to resolve the situation with the orphan envelopes and the letters that are difficult to read or have pages out of sequence by spending significant time in the archives comparing the contents of various folders. My hope is that some letters and envelopes can be reunited, and that the mixed-up letters can be put back in their correct pagination sequence. This will require collaborating with the Center for Adventist Research archivist to create a more organized, useful archival collection. I also plan on doublechecking that all correspondence from Owen to her mother, from both the register series for Owen and the register series for her mother, has been 
accounted for and transcribed. Once I am satisfied that all transcription and inventory issues have been resolved insofar as possible, I will seek to make the letter transcriptions publicly available - whether digitally or as a print monograph - to a wider body of researchers. I would also like to create an index of names mentioned in the letters with appropriate outside sources validating the information where possible. Providing an annotated index of places mentioned in the letters would also be useful to various types of researchers.

While our transcription team has made significant progress in the past four years, there is still much left to do. I am pleased that the team now has better control over methodology, quality, and consistency of transcriptions with the quality control spreadsheet in Google Drive and the required weekly work diary e-mails. I will continue these practices as we work toward completion of the project over the next five years.

Future projects may seek to upload scans of the Owen correspondence onto a publicly accessible digital archive platform, or to transcribe other letters present in the Owen papers, such as the correspondence from her family, friends, students, teachers, and colleagues.

\section{Recommendations}

If I could do this project over again, I would be more systematic about several aspects from the beginning. But sometimes you learn from trial and error; it is not always easy to know what to do until you try it.

For other managers thinking to attempt a large-scale organization, digitization, transcription, or cataloging project, I would recommend taking stock and creating a rough inventory of what needs to be processed before starting any technical work. This will facilitate better organization and communication between a supervisor and other colleagues or employees. Secondly, I would recommend carefully thinking through a workflow before getting started: who will do what, and why, at each step of the process. There will be unanticipated issues that arise during the project but having at least a broad framework of workflows and accountability structures is essential to success.

I strongly recommend exploring the possibilities and functionalities of cloud-based data and document storage systems when in the planning stages of a project. Using these types of flexible, mobile, cloud-based storage systems is even more crucial in situations like the one we are currently experiencing due to COVID-19 where so many librarians and archivists are working from home. The cloud-based sharing of documents (whether with Google Drive or another service such as Dropbox), helps managers and project workers communicate more efficiently and accurately by providing consistent data storage rather than emailing potentially defective generations of Excel spreadsheets back and forth. 
While this project has had its challenges and frustrations, exposing younger scholars to primary source research has been well worth the effort it takes to mentor and manage a large scale, archival-based project. I have found it highly gratifying to see both of my graduate research assistants become engaged with the sources and learn how history is constructed. ${ }^{32}$ It can be tempting to create scholarship by ourselves, especially in the humanities, for fear that a student research assistant may not possess the vision or the skills to understand what the sources are telling them. Yet I know that I would not have been able to attempt a project of this scale and complexity without the help and enthusiasm of my student assistants. With the proper training, and the right attitude, I believe that including students in research and processing projects can help ensure a bright future for the disciplines of both librarianship and musicology.

\section{Notes}

1. Linda Mack, "Biographical Sketch,” Blythe Owen Homepage, https://www.andrews.edu/ library/music/bowenlife.htm (accessed February 12, 2019).

2. Owen studied and worked at various educational institutions in and around Chicago (Hull House, Northwestern University, the Chicago Musical College at Roosevelt University, and Joliet College) as well as maintaining a private piano studio. These activities and institutions are documented throughout her letters to her mother.

3. Per Owen's personnel file held in the Andrews University archives. Gina Lacson (university archivist), e-mail correspondence with the author, July 13, 2018.

4. Per deeds of gift agreement dated June 12, 1991 and April 18, 1997 between Blythe Owen and Andrews University. On file at the Center for Adventist Research (formerly known as the Adventist Heritage Room or the Adventist Heritage Center) which houses the university's archives and special collections. See also the Register of the Blythe Owen Papers: Collection 186 (2015) via the Center for Adventist Research website at http:// www.centerforadventistresearch.org/?mdocs-file $=5587$ Note that the first deed of gift from 1991 is six years before the deed of gift from 1997; the latter is incorrectly cited in the register as the foundational donation for the collection.

5. Even though it was known that Andrews University music librarian Linda Mack was interested in documenting Dr. Owen's life, she was not aware of the estate sale in 1997 until afterward. However, her brother and fellow librarian, Harvey Brenneise, and the music department chair, Peter Cooper, did attend. While the saving of the letters is remarkable, one unfortunate outcome of the auction was that a wicker hamper containing concert programs and other memorabilia from Owen's 1949 trip to study at Fontainebleau, France was sold to another bidder from the community rather than being purchased for the archive. Linda Mack, phone conversation with the author, April 30, 2020. See also Linda Mack, "A SDA Centenarian Musician is Focus of Current Research," ASDAL Action 19, no. 3 (2000): 11-13, https://www.asdal.org/wordpress/wp-content/uploads/newsletters/ASDAL-Action-19.3-Spring-2000.pdf (accessed February 11, 2020).

6. Meredith Jones Gray, e-mail correspondence with the author, April 21, 2016. James (Jim) Ford is the associate director for the Center for Adventist Research. See http:// www.centerforadventistresearch.org/staff/ 
7. Phone conversation between the author and Linda Mack, April 30, 2020. Mack was a former student of Owen's and served as the music librarian at Andrews University from 1993-2012. She has been instrumental in gathering material for the Blythe Owen archival collection, including reaching out to Owen's family and friends, from the late 1990s until the present. See also e-mail correspondence from Donna Kennedy to Linda Mack, May 23, 2008 and between Linda Mack and Peter Cooper, August 1, 2008.

8. See Linda Mack, Blythe Owen Homepage, https://www.andrews.edu/library/music/ bowenlife.htm (updated January 27, 2010).

9. See Box 1, Folder 20 in the 2015 updated Register of the Blythe Owen Papers: Collection 186

10. See a printed spreadsheet index to the letters from the Donna Kennedy collection found in Box 1 Folder 2 of Collection 186. Although I don't remember creating it when I returned to Michigan to help Mack with Owen research during the summer of 2008, I am the most likely author of the spreadsheet; the extant Excel printout bears annotations by Andrews University history professor Brian Strayer dated September 4, 2008.

11. Julie Boyd-Penner transcribed extensive excerpts from the Owen correspondence extant in the collection prior to 2005 for her dissertation, "The Songs for Solo Voice and Piano or Organ of Blythe Owen." My project, however, is the first to systematically transcribe the letters from Owen to her mother, and the first to include the letters donated by Donna Kennedy three years after Penner's dissertation was completed.

12. Family members who have letters and postcards represented in the collection as a whole include Minnie Owen (mother), Herbert (brother), and Theodore X. Cramlet (husband). We are currently working on identifying the letters to and from various friends, such as Rae Constantine Holman, in our quality control index. Musical associates who have correspondence preserved in the collection include teachers Victor Saar, Dent Mowrey, and Alexander Hull.

13. I wish to thank Dr. Gillian Roger for instilling in me the sense that one must be careful to accurately represent the thoughts and voices of people from the past since they are no longer here to defend themselves.

14. Many thanks to Dr. Gary Burdick and the Office of Research and Creative Scholarship at Andrews University for partnering with the James White Library to pay for graduate assistant help via scholarships funded by a Faculty Research Grant. Remuneration of graduate assistant help on this project has consisted of a mix of regular student labor wages supplemented in the summers by grant monies. A financial partnership like this is a fabulous, creative way to make tight budgets stretch further when undertaking a research project. Students can then also list the research scholarship on their résumés as a mark of excellence.

15. Wolfgang Amadeus Mozart, Briefe und Aufzeichnungen Gesamtausgabe, ed. Ulrich Konrad, vol. 8 (Kassel: Bärenreiter, 2005); and Alma Mahler-Werfel, Diaries 1898-1902, trans. and ed. Antony Beaumont (Ithaca, NY: Cornell University Press, 1999).

16. I think here of the many publications on women and American music written in the past thirty years by scholars such as Adrienne Fried Block, Kendra Preston-Leonard, and especially Judith Tick.

17. I found the tips on making transcriptions provided on the United States National Archive's website (https://www.archives.gov/citizen-archivist/transcribe/tips) to be helpful in setting my transcription standards.

18. If one does not transcribe for meaning, instead of the word "little", for example, one could end up with comical nonsense like "li1le" (which is just five little loops of varying height in cursive script if one does not transcribe the jots and tittles of the i's and t's). 
I also chose to silently correct the many times the contraction "it's" is used for the possessive "its" or vice versa. Context and a reading of the entire phrase or idiomatic expression is key to making an accurate transcription.

19. I am using the technical term "holograph" to indicate that a letter was written by Owen herself, in her own handwriting. See Stanley Boorman, sv, "Holograph," Grove Music Online, (2001), https://www.oxfordmusiconline.com/grovemusic/view/10.1093/gmo/ 9781561592630.001.0001/omo-9781561592630-e-0000013248 (accessed May 6, 2020).

20. A similar three-step process of "transcribe, review, and approve" is used by the Smithsonian Institution for their crowd-sourced digital archive transcription program. "General Instructions for Transcription and Review," Smithsonian Digital Volunteers: Transcription Center, https://transcription.si.edu/instructions (accessed May 3, 2020).

21. See, for example, the special roundtable of six papers addressing the use of primary sources in music history pedagogy in the Journal of Music History Pedagogy, 9 no. 1 (2019): 67-117, http://ams-net.org/ojs/index.php/jmhp/issue/view/25 (accessed February 6, 2020). Handling primary sources, and helping prepare them for publication, also implicitly engages students with the six frames of the ACRL's 2016 Framework for Information Literacy for Higher Education: Authority Is Constructed and Contextual, Information Creation as a Process, Information Has Value, Research as Inquiry, Scholarship as Conversation, and Searching as Strategic Exploration. See http://www. ala.org/acrl/standards/ilframework\#authority

22. See James Grier's comments on the mistaken concept of a "pure" Urtext, and the inevitable role of the editor as an interpreter and mediator between the source and the audience. This is not inherently a bad thing - we must own the human messiness of our projects, not just hope for a machine-like, objectively calculated state of work and being. James Grier, The Critical Editing of Music: History, Method, and Practice (Cambridge, MA: Cambridge University Press, 1996), 4-5.

23. The majority of the correspondence consists of multi-page letters (sometimes twentypage epistles) on various sorts of paper and letterhead, but there are postcards and greeting cards interspersed as well.

24. On many occasions in the past, I was asked if any of Minnie's letters to Blythe or anyone else had survived. I didn't used to think there were any, or at least not very many. We can now enumerate that there are, in fact, many more letters from Minnie extant than we once thought, and can say when they were written and in which folder they are kept.

25. WASP is the acronym for the Women's Airforce Service Pilots who flew during WWII. See: United States Army, "Women in the Army," https://www.army.mil/women/history/ pilots.html (accessed February 14, 2020).

26. Dots-per-inch, a standard way of judging the fidelity or quality of a scan or print. Higher DPI translates into better reproduction of an original.

27. For the 1961 moving date to Walla Walla, see: Linda Mack, "Biographical Sketch.” Also, Gina Lacson (Andrews University archivist), e-mail correspondence with the author, July 13, 2018. Lacson indicates that Owen's denominational service record for the North American Division of the Seventh-day Adventist church lists September 25, 1961 as the start date for Owen's employment at Walla Walla College. A denominational service record allows for the portability of retirement benefits if a person works at more than one denominationally-affiliated institution during the course of a career, such as Owen did by twice working for Walla Walla College and then Andrews University.

28. Lacson, e-mail of July 13 2018, states that Owen's start date at Andrews University was June 21, 1965; My Heritage Library Edition, "Minnie B Owen (born Perkins)," https:// records.myheritagelibraryedition.com/research/record-40001-187385066/minnieb-owen-born-perkins-in- familysearch-family-tree (accessed February 14, 2020). 
29. See Box 5, Folders 13-15 in the 2015 updated Register of the Blythe Owen Papers: Collection 186. These contain (as-yet) undated letters, postcards, and envelopes.

30. E-Mail correspondence with the author, February 11, 2020.

31. As of July 2020, at the time of writing this article, my current graduate research assistant has been sheltering at home in another country since March. As shelter-in-place restrictions are relaxed in the coming weeks, I hope to collaborate with the archival staff to acquire scans so he can continue his work from home since he has now run out of scans from which to transcribe. I am grateful I can extend a Faculty Research Grant scholarship to him for his assistance at a moment where I have been required to lay off the rest of my student staff without wages until August.

32. Indeed, my entire rotating team of eight to ten student assistants has been exposed to the process of performing original research from primary sources over the past four years thanks to this project. Thus, the positive influence of conducting an original research project are more widespread than just the effect on the principle research assistants.

\section{Disclosure statement}

No potential conflict of interest was reported by the author.

\section{Funding}

This work was supported by Andrews University - Office of Scholarly and Creative Research Faculty Research Grant [11-2011-xxxx-75-201138]. 